\title{
A clinical comparison of laparoscopic versus open appendectomy for the treatment of complicated appendicitis: historical cohort study
}

\author{
Tomoya Takami ${ }^{1}$ (i) $\cdot$ Tomoyuki Yamaguchi $^{1} \cdot$ Hiroyuki Yoshitake ${ }^{1} \cdot$ Kotaro Hatano $^{1} \cdot$ Naoki Kataoka $^{1}$. \\ Masafumi Tomita ${ }^{1} \cdot$ Shinichiro Makimoto ${ }^{1}$
}

Received: 27 November 2018 / Accepted: 30 January 2019 / Published online: 2 February 2019

(c) The Author(s) 2019

\begin{abstract}
Background Appendectomy is one of the most common operations. Laparoscopic appendectomy (LA) is considered firstline treatment, but the use of LA for treatment of complicated appendicitis remains controversial. Here, we performed a retrospective analysis to compare clinical outcomes between patients treated with LA and those who underwent open appendectomy (OA).

Methods Data for 179 patients who underwent an operation for the treatment of complicated appendicitis at our hospital between 2011 and 2017 were retrospectively analyzed. The selection included 89 patients who underwent a conventional appendectomy and 90 patients who were treated laparoscopically. Outcome measures such as mean operative time, blood loss, time until oral intake duration of hospital stay, and postoperative complications were analyzed. Logistic regression analysis was performed to determine the concurrent effects of the examined factors on the rate of postoperative complications. Results The mean ages of patients in the OA and LA groups were 50.17 \pm 22.77 and $50.13 \pm 25.84$ year. Mean operative times were longer in the LA group than OA $(10.2 .56 \pm 44.4$ versus $85.4 \pm 43.11 \mathrm{~min} ; p=0.009)$. The duration of hospital stay was shorter for the LA group $(9.61 \pm 5.57$ versus $12.19 \pm 8.4 ; p=0.016)$. There were no significant differences in return to consumption of oral intake between the LA and OA groups $(2.03 \pm 1.66$ versus $2.48 \pm 2.17 ; p=0.123)$. Multivariable analysis found that the rate of postoperative complications was significantly reduced for the LA group, in comparison with the postoperative-complication rate of the OA group ( $16.7 \%$ versus $27 \%$; odds ratio 0.376 ; $95 \%$ CI $0.153-0.923 ; p=0.0327$ ). Conclusions These results suggest that LA is a safe and efficient operative procedure that provides clinically beneficial advantages in comparison with OA. Thus, when possible, appendectomy for complicated appendicitis should be attempted using a laparoscopic approach.
\end{abstract}

Trial registration Retrospectively registered.

Keywords Complicated appendicitis · Laparoscopic appendectomy $\cdot$ Open appendectomy $\cdot$ Acute appendicitis

\section{Background}

Acute appendicitis is a common condition that occurs in all age groups $[1,2]$. Among them, complicated appendicitis requires surgical intervention within the abdomen. First described by McBurney in 1894, open appendectomy $(\mathrm{OA})$ is an established safe and effective procedure for treating acute appendicitis for over a century [3]. Conversely,

Tomoya Takami

tomoya0takami@gmail.com

1 Department of General Surgery, Kishiwada Tokushukai Hospital, 4-27-1 Kamoricho, Kishiwada, Osaka 596-0042, Japan laparoscopic appendectomy (LA), which was first performed by Semm in 1983 [2], has recently become a well-accepted surgical approach and has been reported to shorten the duration of hospital stay, improve postoperative recovery time, yield better cosmetic outcomes, and mitigate pain [4-6]. However, the authors of several studies in which LA was used for treating complicated appendicitis warn of the risk of infection, with particular reference to intra-abdominal abscess (IAA) and superficial wound infection [7-9]. Thus, the use of LA for complicated appendicitis has remained a subject of debate.

This investigation sought to compare clinical outcomes, including mean operative time, blood loss, time to oral intake, duration of hospitalization, and postoperative 
complications, in patients with complicated appendicitis who underwent either LA or OA.

\section{Methods}

\section{Study design and participants}

This single-center, retrospective, observational study involved patients with a diagnosis of appendicitis admitted to the Department of General Surgery, Kishiwada Tokushukai Hospital, Osaka, Japan between January 2011 and December 2017. Complicated appendicitis was defined as acute appendicitis in which a visible perforation was evident in the appendix, with the presence of free pus, IAA. The type of surgical procedure was determined by the operating surgeon. All patients were administered intravenous antibiotics (second-generation cephalosporin) preoperatively, which were continued postoperatively until inflammatory response had subsided, as shown by clinical and laboratory findings such as resolution of fever, pain, bowel movement, oral intake, white blood cell (WBC) count, and C-reactive protein (CRP) level.

This study included 179 patients: 89 patients underwent $\mathrm{OA}$ and 90 patients underwent LA. Patients with converted OA were included in the LA group. For each patient, the collected clinical data, including the patient's age, gender, comorbidity, and body mass index (BMI), WBC count, CRP level, duration of hospitalization, time to oral intake, and postoperative complications, were all documented. Duration of surgery, operative time, and intraoperative blood loss was also recorded. Postoperative complications were recorded for each patient in the clerking pro forma during hospitalization and at follow-up. Postoperative complications of wound infection, IAA, intraperitoneal infection, paralytic ileus, and mortality rates were assessed. Wound infection, taken to be any indication of infection, included redness or purulent or seropurulent discharge from the incision site necessitating suture removal or antibiotic treatment, or any sign of wound dehiscence. IAA was defined as purulent discharge positive on culture that is clearly from intra-abdominal fluid obtained at surgery and confirmed as fluid collection on radiology, with localized signs of infection. Intraperitoneal infection was defined as infection within the peritoneal cavity in the absence of localized fluid collection. Paralytic ileus was defined as a condition in which oral intake of food and water was restricted for a few days, due to abdominal distension, nausea, and vomiting.

\section{Surgery}

A standard technique for LA was employed, using a threetrocar technique (one $12-\mathrm{mm}$ and two 5-mm trocars). A 12-mm umbilical port was introduced via the open method, thus creating pneumoperitoneum; two 5-mm ports were used, one in the left lower abdomen and the other in the left lateral region (Fig. 1) and a 5-mm flexible laparoscope was used to visualize the operation sites. The intra-abdominal space was insufflated with carbon dioxide $\left(\mathrm{CO}_{2}\right)$ to a pressure of $10 \mathrm{mmHg}$. With the patient in the Trendelenburg position and slightly rotated to the left, the mesoappendix was dissected with an ultrasonically activated scalpel and the appendix was divided using an endolinear stapler. The appendix was removed by means of an endoscopic retrieval bag was inserted through the umbilical port to avoid contamination.

For OA, the procedure was performed using the conventional methodology, with intra-abdominal access via a McBurney incision and a muscle-split peritoneal incision. After ligation of the mesoappendix, the stump of the appendix was divided with absorbable sutures, without the use of a purse-string suture. Drain placemenet was at the discretion of the operating surgeons. All collected specimens were sent for histopathological examination. Patients in both groups were encouraged to ambulate from postoperative day 1 . Oral intake was commenced as soon as the patient could tolerate, with subsequent discharge home on satisfactory recovery of both oral intake and physical activity. For both LA and $\mathrm{OA}$, the mean operative time (in minutes) was measured, beginning from the time of the first skin incision to the time

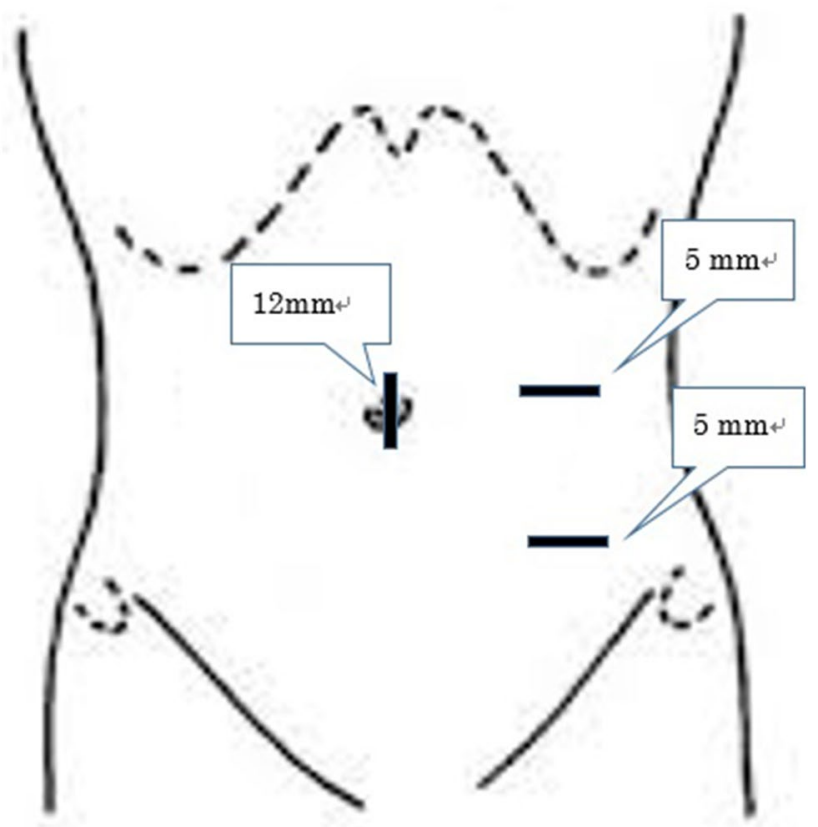

Fig. 1 Diagrammatic sketch showing the placement of the ports in the present case. A $12 \mathrm{~mm}$ camera port was inserted just superior to the umbilicus. Two $5 \mathrm{~mm}$ assistant ports were used, one in the left lower abdomen and the other in the left lateral region 
of the application of the last skin suture. The duration of hospitalization was determined as the number of nights spent in hospital after admission.

\section{Statistical analysis}

All statistical analysis was performed using EZR software (Easy R; Saitama Medical Center, Jichi Medical University, Saitama, Japan), a graphical user interface for R programming language (The R Foundation for Statistical Computing, Vienna, Austria). Specifically, it is a modified version of the $\mathrm{R}$ commander, which incorporates frequently used statistical functions in biostatistics [10]. Between-group comparisons were made on an intention-to-treat basis; patients in the LA group who required conversion to OA were not excluded from the analysis. Continuous variables, such as age, BMI, WBC count, CRP level, mean operative time, blood loss, time to oral intake, and duration of hospitalization, are presented as mean \pm standard deviation of mean. The means of continuous variables were compared using the unpaired twotailed $t$ test. Postoperative complications were assessed using multivariate logistic regression analysis (risk ratio) with a two-tailed $95 \%$ confidence interval (CI), and a $p \leq 0.05$ was considered significant.

\section{Results}

This study included 179 patients. OA was performed for 89 cases $(49.7 \%)$ and LA for 90 cases $(50.3 \%)$. The OA group comprised 56 males and 33 females, and the LA group comprised 62 males and 28 females. Mean age was $50.17 \pm 22.77$ years for the OA group and $50.13 \pm 25.84$ years for the LA group. The mean BMI was $22.42 \pm 4.9$ for the OA group and $22.3 \pm 4.25$ for the LA group. Clinical characteristics and other variables, such as age, sex, BMI, comorbidities, WBC count, and CRP level, did not differ significantly

Table 1 Clinical characteristics of patients

\begin{tabular}{|c|c|c|c|}
\hline Age (years), mean \pm SD & OA $(n=89)$ & LA $(n=90)$ & $p$ value \\
\hline Sex ratio $(\mathrm{M}: \mathrm{F})$ & $50.17 \pm 22.77$ & $50.13 \pm 25.84$ & 0.992 \\
\hline Body mass index $\left(\mathrm{kg} / \mathrm{m}^{2}\right)$ & $56: 33$ & $62: 28$ & \\
\hline $\begin{array}{l}\text { Comorbidity (diabetes mel- } \\
\text { litus) }\end{array}$ & $22.42 \pm 4.9$ & $22.3 \pm 4.25$ & 0.874 \\
\hline $\begin{array}{l}\text { Preoperative WBC }(\times 1000 / \\
\mu \mathrm{L})\end{array}$ & 9 & 6 & 0.433 \\
\hline Preoperative CRP (mg/dL) & $12.82 \pm 4.47$ & $13.84 \pm 5.32$ & 0.166 \\
\hline Drainage insertion & $\begin{array}{l}12.73 \pm 9.46 \\
72(80.9 \%)\end{array}$ & $\begin{array}{l}12.58 \pm 9.32 \\
45(50 \%)\end{array}$ & 0.912 \\
\hline
\end{tabular}

$W B C$ white blood cell, $C R P$ C-reactive protein between the two groups. Drains were placed at surgery in $80.9 \%$ of OA and $50 \%$ of LA patients (Table 1).

Mean operative time was $85.4 \pm 43.11 \mathrm{~min}$ for the OA group and $102.56 \pm 44.4 \mathrm{~min}$ for the LA group, which was longer in the LA group $(p=0.009)$. On the other hand, mean intraoperative blood loss of $29.64 \pm 62.97 \mathrm{~mL}$ for the LA group was significantly less than mean blood loss of $74.79 \pm 168.55 \mathrm{~mL}$ for the OA group $(p=0.018)$. The OA group took a mean of $2.48 \pm 2.17$ days to start consuming oral intake, whereas the LA group took a mean of $2.03 \pm 1.66$ days, which was not significant $(p=0.123)$. Total hospitalization duration was significantly shorter in the LA group (mean $9.61 \pm 5.57$ days) in comparison with the OA group (mean $12.19 \pm 8.4$ days) ( $p=0.016$, Table 2$)$.

The overall incidence of complications was greater in the OA group, compared with that of the LA group. Specifically, 24 complications occurred among patients in the OA group versus 15 complications among patients in the LA group (Table 3). Multivariable analysis revealed a significantly reduced rate of postoperative complications in the LA group, compared with that of the OA group ( $16.7 \%$ versus $27 \%$; odds ratio 0.376 ; $95 \%$ CI $0.153-0.923 ; p=0.0327$ ).

\section{Discussion}

The most frequently occurring intra-abdominal condition that requires emergency surgical treatment is acute appendicitis is [11]. Recently, several authors have proposed that

Table 2 Comparison of primary outcome measures

\begin{tabular}{lccc}
\hline Outcome measures & OA $(n=89)$ & LA $(n=90)$ & $p$ value \\
\hline Mean operative time (min) & $85.4 \pm 43.11$ & $102.56 \pm 44.4$ & 0.009 \\
Blood loss (mL) & $74.79 \pm 168.55$ & $29.64 \pm 62.970 .018$ \\
$\begin{array}{l}\text { Time until oral intake } \\
\quad \text { days) }\end{array}$ & $2.48 \pm 2.17$ & $2.03 \pm 1.66$ & 0.123 \\
$\begin{array}{l}\text { Duration of hospitalization } \\
\quad \text { days })\end{array}$ & $12.19 \pm 8.4$ & $9.61 \pm 5.57$ & 0.016 \\
\hline
\end{tabular}

Table 3 Comparison of postoperative complications

\begin{tabular}{llll}
\hline & OA $(n=89)$ & LA $(n=90)$ & $p$ value \\
\hline Postoperative complications & $24(27 \%)$ & $15(16.7 \%)$ & 0.0327 \\
Paralytic ileus & 8 & 7 & 0.79 \\
Intra-abdominal abscess & 6 & 1 & 0.064 \\
Intraperitoneal infection & 3 & 1 & 0.682 \\
Wound infection & 7 & 2 & 0.09 \\
Mortality & 0 & 2 & \\
Other & $1 * 1$ & $1 * 2$ & \\
\hline
\end{tabular}

*1 cerebral infarction, $* 2$ gastric ulcer 
the advantages of using laparoscopy for the treatment of cholelithiasis could also be applicable in the treatment of appendicitis $[12,13]$. Furthermore, the effectiveness of the laparoscopic approach for complicated appendicitis has been extensively investigated [14-17].

Johnson argues that any new surgical procedure must be shown to be safe, easy, and rapid to perform, especially when there is a well-established and safe alternative [18]. Several studies have shown that the main benefits of LA for complicated appendicitis include prevention of wound infection and shortened duration of hospitalization $[7,15,17,19]$. On the other hand, operative time and postoperative complications associated with LA have been identified as potential drawbacks of this surgical approach [19, 20]. Regarding operative time, some reports have stated that LA takes longer than OA $[7,16,21]$. Similarly, in our study, mean operative time was about 17.2 min longer in the LA group, versus that of the OA group. The reportedly longer operative time is likely, because during the early period of adoption of this approach, LA took more time, while surgeons developed the necessary surgical skills and technique familiarity to become specialists [22, 23]. Recently, the expertise and surgical technical skills of the surgeons have been improved by performing a wide range of laparoscopic surgeries.

We found that mean blood loss was significantly less in the LA group than in the OA group. This is likely, because LA offers a better surgical field of view than conventional OA. This allowing bleeds to be noticed and dealt with more quickly with the LA approach. The introduction of oral intake was not significant in our study. However, several studies have stated that LA occurred sooner for patients [23, 24].

Duration of hospitalization is an important factor that directly impacts the patients' finances and overall wellbeing. Our findings show that the duration of hospitalization was significantly shorter in the LA group $(p=0.016)$ and this is consistent with the study of some studies [16, 21, 24]. However, the association of LA with a shorter duration of hospitalization remains debatable [25].

In our study, the postoperative-complication rates were significantly lower in the LA group $(p=0.0327)$. In our study, the rate of wound infection was not significant difference, but was lower in the LA group $(p=0.09)$. Wound infection occurs rather frequently and may not be considered a serious complication; it, however, has strongly affects the convalescence period and quality of life. The low incidence of wound infections in the LA group may be due to the extraction of the infected appendix using the endoscopic retrieval bag, which allows no opportunity for the inflamed organ to be in direct contact with the wound, rather than by direct extraction through the surgical wound, which does allow such contact [26]. On the other hand, IAA is a severe and life-threatening complication, and a higher incidence of IAA following surgery is associated with the LA [9, 27], which has possibly hampered LA being adopted as a standard procedure for the treatment of complicated appendicitis. Several hypotheses have been proposed to clarify this phenomenon, including mechanical intraperitoneal spread of bacterial facilitated by $\mathrm{CO}_{2}$ insufflation, especially in ruptured appendix, an inadequate learning curve of the surgeon, and the need for thorough irrigation instead of simple suctioning of the infected area in the case of severe peritonitis (where improper technique can often lead to contamination of the whole abdominal cavity) [5, 28]. In our study, the IAA rate was not significant difference, but was lower in the LA group $(p=0.064)$. A similar report has been recently [16, 17]. This finding might be due to the improvement of surgeons' laparoscopic skills, as suggested previously [29, 30].

The choice regarding the use ligation or a stapling device to close of the stump of the appendix in cases of perforated appendicitis remains controversial [31,32]. Some investigations have stated that leakage of infected content and breakdown of the stump of the appendix could be avoided using an Endo-GIA stapler ${ }^{\mathrm{TM}}$ (Medtronic, Medtronic Parkway, Minneapolis, MN) [33, 34]. Thus, an endo linear stapler was used for appendiceal stump closure for our LA cases.

Overall, clinical outcomes for patients who underwent LA were superior to those of patients who underwent OA. We propose that, in managing a patient with appendicitis, the surgeon should consider LA as the first-line procedure.

This study has several limitations. Specifically, patients were not randomized to the LA and OA groups, and the choice of the surgical procedure was dependent on the operating surgeon. The selection of cases to undergo LA may be biased by factors such as patient age at presentation, duration of symptoms, and the surgeon's preference. Furthermore, this study was carried out in a single institution and with relatively small sample size.

\section{Conclusions}

Our findings suggest that LA is a safe and efficient surgical procedure, which provides clinically beneficial advantages in comparison with the outcomes associated with OA. Therefore, we suggest that appendectomy be attempted laparoscopically for treating complicated appendicitis. Further investigation is required to elucidate the efficiency of LA in the treatment of complicated appendicitis.

Funding There are no financial relationships to disclose.

\section{Compliance with ethical standards}

Conflict of interest The authors declare that they have no competing interests. 
Informed consent No informed consent necessary, as study was retrospective.

OpenAccess This article is distributed under the terms of the Creative Commons Attribution 4.0 International License (http://creativeco mmons.org/licenses/by/4.0/), which permits unrestricted use, distribution, and reproduction in any medium, provided you give appropriate credit to the original author(s) and the source, provide a link to the Creative Commons license, and indicate if changes were made.

\section{References}

1. Addiss DG, Shaffer N, Fowler BS, Tauxe RV. The epidemiology of appendicitis and appendectomy in the United States. Am J Epidemiol. 1990;132:910-25.

2. Seem K. Endoscopic appendectomy. Endoscopy. 1983;15:59-64.

3. McBurney C.The incision made in the abdominal wall in case of appendicitis, with a description of a new method of operating. Ann Surg. 1894;20:38-43.

4. Golub R, Siddiqui F, Pohl D. Laparoscopic versus open appendectomy: a metaanalysis. J Am Coll Surg. 1998;186:545-53.

5. Chung RS, Rowland DY, Li P, Diaz J. A meta-analysis of randomized controlled trials of laparoscopic versus conventional appendectomy. Am J Surg. 1999;177:250-6.

6. Garbutt JM, Soper NJ, Shannon WD, Botero A, Littenberg B. Meta-analysis of randomized controlled trials comparing laparoscopic and open appendectomy. Surg Laparosc Endosc. 1999;9:17-26.

7. Lin HF, Lai HS, Lai IR. Laparoscopic treatment of perforated appendicitis. World J Gastroenterol. 2014;20:14338-47.

8. Thereaux J, Veyrie N, Corigliano N, Servajean S, Czernichow $\mathrm{S}$, Bouillot J. Is laparoscopy a safe approach for diffuse appendicular peritonitis? Feasibility and determination of risk factors for postoperative intra-abdominal abscess. Surg Endosc. 2014;28:1908-13.

9. Yeom S, Kim MS, Park S, Son T, Jung YY, Lee SA et al. Comparison of the outcomes of laparoscopic and open approaches in the treatment of periapendiceal abscess diagnosed by radiologic investigation. J Laparoendosc Adv Surg Tech A. 2014;24:762-9.

10. Kanda Y. Investigation of the freely available easy-to-use software 'EZR' for medical statistics. Bone Marrow Transplant. 2013;48:452-8.

11. Kehagias I, Karamanakos SN, Panagiotopoulos S, Panagopoulos K, Kalfarentzos F. Laparoscopic versus open appendectomy: which way to go? World J Gastroenterol. 2008;14:4909-14.

12. Fritts LL, Orlando R. Laparoscopic appendectomy. A safety and cost analysis. Arch Surg. 1993;128:521-5.

13. Nowzaradan Y, Westmoreland J, McCarver CT, Harris RJ. Laparoscopic appendectomy for acute appendicitis: indication and current use. J Laparoendosc Surg. 1991;1:247-57.

14. Taguchi Y, Komatsu S, Sakamoto E, Norimizu S, Shingu Y, Hasegawa $\mathrm{H}$. Laparoscopic versus open surgery for complicated appendicitis in adults: a randomized controlled trial. Surg Endosc. 2016;5:1705-12.

15. Li P, Han Y, Yang Y, Guo H, Hao F, Tang Y,et al.Retrospective review of laparscopic versus open surgery in the treatment of appendiceal abscess in pediatric patients:Laparoscopic versus open surgey for appendiceal abscess. Medicine. 2017;96(30):e7514.
16. Athanasiou C, Lockwood S, Markides GA. Systematic review and meta-analysis of laparoscopic versus open appendicectomy in adults with complicated appendicitis: an update of the literature. World J Surg. 2017;41(12):3083-99.

17. Zhang S, Du T, Jiang X, Song C. Laparoscopic appendectomy in children with perforated appendicitis: a meta-analysis. Surg Laparosc Endosc Percutan Tech. 2017;27(4):262-6.

18. Johnson A. Laparoscopic surgery. Lancet. 1997;349:631-5.

19. Bonanni F, Reed J, Hartzell G, Trostle D, Boorse R, Gittleman M, et al. Laparoscopic versus conventional appendectomy. J Am Coll Surg. 1994;179:273-8.

20. Frazee RC, Bohannon WT. Laparoscopic appendectomy for complicated appendicitis. Arch Surg. 1996;131:509-11.

21. Dai L, Shuai J.Laparoscopic versus open appendectomy in adults and children: a meta-analysis of randomized controlled trials. UEG J. 2017;5(4):542-553.

22. Kim SY, Hong SG, Roh HR, Park SB, Kim YH, Chae GB. Learning curve for a laparoscopic appendectomy by a surgical trainee. J Korean Soc Coloproctol. 2010;26:324-8.

23. So JB, Chiong EC, Chiong E, Cheah WK, Lomanto D, Goh P, et al. Laparoscopic appendectomy for perforated appendicitis. World J Surg. 2002;26:1485-8.

24. Shimoda M, Maruyama T, Nishida K, Suzuki K, Tago $\mathrm{T}$, Shimazaki J, et al. Comparison of clinical outcome of laparoscopic versus open appendectomy, single center experience.2018;4(5):e00635.

25. Guller U, Hervey S, Purves H, Muhlbaier LH, Peterson ED, Eubanks S,et al. Laparoscopic versus open appendectomy: outcomes comparison based on a large administrative database. Ann Surg. 2004;239:43-52.

26. Minutolo V, Licciardello A, Di Stefano B, Arena M, Arena G, Antonacci V. Outcomes and cost analysis of laparoscopic versus open appendectomy for treatment of acute appendicitis: 4-years experience in a district hospital. BMC Surg. 2014. https://doi. org/10.1186/1471-2482-14-14.

27. Lim SG, Ahn EJ, Kim SY, Chung IY, Park JM, Park SH,et al. A clinical comparison of laparoscopic versus open appendectomy for complicated appendicitis. J Korean Soc Coloproctol. 2011;27:293-7.

28. Biondi A, Di Stefano C, Ferrara F, Bellia A, Vacante M, Piazza L. Laparoscopic versus open appendectomy: a retrospective cohort study assessing outcomes and cost-effectiveness. World J Emerg Surg. 2016. https://doi.org/10.1186/s13017-016-0102-5.

29. Markides G, Subar D, Riyad K. Laparoscopic versus open appendectomy in adults with complicated appendicitis: systematic review and meta-analysis. World J Surg. 2010;34:2026-40.

30. Ball CG, Kortbeek JB, Kirkpatrick AW. Mitchell P.Laparoscopic appendectomy for complicated appendicitis: an evaluation of postoperative factors. Surg Endosc. 2004;18:969-73.

31. Kazemier G, in't Hof KH, Saad S, Bonjer HJ, Sauerland S. Securing the appendiceal stump in laparoscopic appendectomy: evidence for routine stapling? Surg Endosc. 2006;20:1473-6.

32. Sahm M, Kube R, Schmidt S, Ritter C, Pross M, Lippert H. Current analysis of endoloops in appendiceal stump closure. Surg Endosc. 2011;25:124-9.

33. Piskun G, Kozik D, Rajpal S, Shaftan G, Fogler R. Comparison of laparoscopic, open, and converted appendectomy for perforated appendicitis. Surg Endosc. 2001;15:660-2.

34. Katkhouda N, Friedlander MH, Grant SW, Achanta KK, Essani $\mathrm{R}$, Paik P,et al. Intraabdominal abscess rate after laparoscopic appendectomy. Am J Surg. 2000;180:456-9. 